\title{
X chromosome abnormal inactivation: a unique factor for women's diseases?
}

\author{
"In addition to women's unique diseases in reproductive organs, \\ many other diseases also have clear gender preferences. Whether \\ this can be explained by the unique process of $\mathrm{Xi}$ in women is \\ an interesting question."
}

\begin{abstract}
First draft submitted: 4 January 2016; Accepted for publication: 8 January 2016; Published online: 1 April 2016
\end{abstract}

Keywords: abnormal X chromosome gene expression • cancer risk • skewed X-chromosome inactivation $\bullet$ tumor progression and outcome $\bullet \mathbf{X}$ chromosome inactivation $\bullet \mathbf{X}$ chromosome loss $\bullet$ X-linked disorder

$\mathrm{X}$ chromosome inactivation (XCI) is unique gene regulation mechanism to counter the potential dosage effect of two X chromosomes in women's cells instead of one in men's. The inactivated $\mathrm{X}$ chromosome $(\mathrm{Xi})$ is highly condensed and viewed as a Barr body in microscope. Most genes (>85\%) on this $\mathrm{Xi}$ are in a state of transcriptional silence and leave the remaining escaping the inactivation and likely performing needed functions. The $\mathrm{XCI}$ process is a typical example of epigenetic control where DNA coding sequence is not changed but gene transcription is modified through DNA and histone modifications and $3 \mathrm{D}$ wrapping. The $\mathrm{XCI}$ is regulated by an X-inactivation center, a key locus that is required for the initiation of $\mathrm{X}$ inactivation with a long noncoding RNA XIST [1]. On the $\mathrm{X}$ chromosome to be inactivated, a large number of the XIST RNA molecules are expressed, deposited, and spread along [2]. The afterward recruitment of polycomb proteins, occurrence of DNA methylation, and histone modifications lead to the condensation and inactivation of the $\mathrm{X}$ chromosome [3]. New advances for the complex epigenetic changes have been made in recent years [3,4]. Once established, the XCI can be stably inherited in the differentiated cells [5].

The XCI is a random process, in other words, the two $\mathrm{X}$ chromosomes from mother $(\mathrm{Xm})$ and father $(\mathrm{Xp})$ have an equal chance to be inactivated and in the end there are about
$50 \%$ women's cells with Xm inactivated and other $50 \%$ with $\mathrm{Xp}$ inactivated, although it is more theoretical. Any significant deviation from this mosaic state is termed as skewed $\mathrm{X}$-chromosome inactivation (SXCI), which is clinically relevant and is a hot topic of research. There are more than 1100 genes located on human $\mathrm{X}$ chromosome, which take about $5 \%$ of total human genes; however, the chromosome has accumulated a disproportionately higher number of genes concerned with neural development and mental functions [6].

The tightly controlled inactivation process can go awry and cause diseases or it can be a subsequent event of another disease. Different types and degrees of abnormal Xi exist. The commonly studied one is SXCI where one of the $\mathrm{X}$ chromosomes (Xp or $\mathrm{Xm}$ ) is significantly favored for inactivation over another. The SXCI may not always be bad and it actually can have three outcomes. If both $\mathrm{X}$ chromosomes are healthy (i.e., without a mutation), there would be not much impact. If one of the $\mathrm{X}$ chromosomes has a defect but the skewed inactivation happens to be on this chromosome, the defect might be silenced and the inactivation may have a protective effect. The worse and more clinically relevant scenario might be the case in which skewed inactivation occurs in the healthy chromosome but leaves the defective one active. An array of studies has shown
Epigenomics

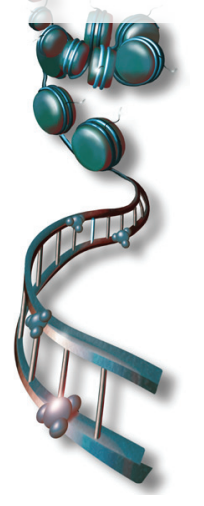

Cuijiao Wu

Department of Histology \& Embryology, Qingdao University Medical School, Qingdao, Shandong, China

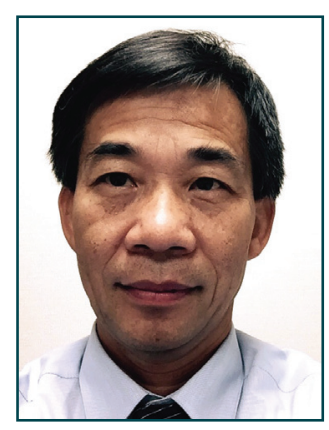

Zhifu Sun

Author for correspondence: Department of Health Sciences Research, Mayo Clinic, Rochester, MN, USA sun.zhifu@mayo.edu 
SXCI is associated with disease development, clinical phenotypes or outcomes. For example, extremely SXCI (95\% or above) is associated with a very higher incidence (>four-times) of idiopathic recurrent spontaneous abortion from a meta-analysis of 12 datasets [7]. PHACE syndrome is a developmental disorder with unknown cause. Studies show consistent SXCI in the unaffected mother but consistent random X-inactivation in the affected proband, suggesting that the mother is protected through favorable skewed X-inactivation but the proband is not [8]. X-linked dominant Rett syndrome is another example of modifying effect of SXCI on manifestation of clinical phenotype [9]. SXCI has been extensively studied for women's cancer risk such as breast or ovarian cancer. These studies are mostly epidemiologic using blood leukocytes. Early data shows that SXCI occurs more in individuals with BRCA1 mutation compared with control subjects, and among the patients with breast or ovarian cancer, the SXCI is found to be significantly associated with age at diagnosis [10]. The latter is interesting as studies also find that SXCI increases with aging in normal population [11]. Contrary to the notion, SXCI is reported in young females with breast cancer but no difference is found for those in regular breast occurring ages [12-14]. Ovarian cancer patients with invasive tumors have high skewed X inactivation compared with those with borderline cancer and healthy control subjects [15]. The significant association is also observed in other cancer such as early development of lung cancer in females [16] and esophageal cancer [17]. Certainly not all studies are positive. A study assessing SXCI between cases with BRCA1 mutation with those without did not see any difference [18]. SXCI appears not different between patients with cervical cancer and age-matched controls [19].

The inconsistencies can be the result of multiple factors. Cancer initiation and development in different organs may differ. SXCI may play a role in one organ but may not in another. Second, many studies may not have a sufficient sample size or power to detect the association or it may be confounded by other factors such as age. Most studies use blood lymphocytes as a surrogate; however, they are highly regenerative with a short life span and it is questionable if they are representative of the tissue origin of women's cancer like breast and ovarian. Last and most importantly, SXCI has either a damaging or protective effect depending on the location of a defective allele and the X chromosome skewed. As our knowledge for risk alleles is limited, it is impossible to conduct allele-specific inactivation analysis. Without that information, the indiscriminating SXCI analysis may turn out to be null association as the protective and damaging effects cancel each other out. With tech- nology and knowledge advance, we expect this is going to be changed. Combined genotype and SXCI analysis indeed suggests there is an additive interaction between the two and the risk allele along SXCI significantly increases breast cancer risk [20]. This will also help us to understand why some X-linked genetic disorders do not have clinical presentation and SXCI might be one of the underlying mechanisms.

Loss or gain of additional $\mathrm{X}$ chromosome is a severe genetic disorder that is well characterized clinically such as 46, XX-maleness, 47, XXX, Klinefelter syndrome (47, XXY) and Turner syndrome (45, X). Patients with these karyotypes generally have developmental abnormalities but often are not lethal, with many living a relatively normal life. For example, patients with tripple $\mathrm{X}$ syndrome (47, XXX) may have low IQ and higher stature but can be fertile with normal children [21]. One of the reasons may be the normal X inactivation. If there is more than one $\mathrm{X}$ chromosome, the extra ones should be all inactivated randomly. However, cells with multiple $\mathrm{X}$ tend to be compromised for the inactivation process and can leave more than one active X chromosomes (Xa). In analysis of a 49, XXXXX girl, the $4 \mathrm{Xs}$ are found to be maternal and preferentially inactivated but incomplete, causing the patient's severe physical phenotype and mental retardation [22].

Abnormal Xi has been long recognized in cancer; however, how it happens and what are the implications are little known. Loss of $\mathrm{Xi}$ with two co-existing active ones was described in breast cancer cell lines long time ago [23]. The original Xi likely got lost and duplication of Xa made both active. The loss appeared cancer subtype specific. By observing the disappearance of the Barr body in cancer cells, it was found that it occurred in more than half of the sporadic basal-like breast cancer, the subtype without expressing ER, PR and Her 2 and in high grade (i.e., more aggressive). The Barr body disappearance was accompanied with two $\mathrm{Xa}$, either from duplication of the $\mathrm{Xa}$ or reactivation of Xi. Both may lead to a small subset of X chromosomal genes overly expressed [24]. Genetic instability may cause Xi loss physically [25], which is not surprising considering chromosome gain or loss is common in cancer cells. The interesting question is why there is accompanying Xa duplication. A more plausible mechanism may be that $\mathrm{Xi}$ process dysfunctions and then leads to reactivation of the $\mathrm{Xi}[24,26]$. Through highresolution sequence techniques, a recent study provides strong evidence of epigenetic instability of the inactive $\mathrm{X}$ chromosome [27]. Although the underlying mechanisms differ, the overall result from either tends to be similar, in other words, increased expression of some or all X-linked genes. The overdosing could potentially provide a selective advantage and promote can- 
cer development or progress. From both breast cancer cell lines and primary tumors, a core set of commonly changed genes likely associated with abnormal $\mathrm{X}$ inactivation was characterized [26]. More importantly, survival analysis of the primary breast tumors found important genes associated with tumor progression and aggressiveness [26]. Loss of XCI is more common in endometrial serous adenocarcinoma and associated with increased expression of cancer-testis antigens. Tumors with two Xa render worse clinical outcome to patients [28]. High-grade serous ovarian adenocarcinomas with loss of XCI showed more aggressive behavior and led to shorter patient survival [29].

\section{"More importantly, survival analysis of the primary breast tumors found important genes associated with tumor progression and aggressiveness."}

Recent evidence shows that reprogramming of somatic cells to naive pluripotency is coupled to $\mathrm{X}$ chromosome reactivation and at molecular level DNA demethylation and removal of XIST silencing [29,30]. One of unique features in cancer cells is the loss or

\section{References}

1 Brown CJ, Hendrich BD, Rupert JL et al. The human XIST gene: analysis of a $17 \mathrm{~kb}$ inactive $\mathrm{X}$-specific RNA that contains conserved repeats and is highly localized within the nucleus. Cell 71(3), 527-542 (1992).

2 Kalantry S, Purushothaman S, Bowen RB, Starmer J, Magnuson T. Evidence of XIST RNA-independent initiation of mouse imprinted X-chromosome inactivation. Nature 460 (7255), 647-651 (2009).

3 Chaligne R, Heard E. X-chromosome inactivation in development and cancer. FEBS Lett. 588(15), 2514-2522 (2014).

4 Briggs SF, Reijo Pera RA. X chromosome inactivation: recent advances and a look forward. Curr. Opin. Genet. Dev. 28, 78-82 (2014).

5 Okamoto I, Otte AP, Allis CD, Reinberg D, Heard E. Epigenetic dynamics of imprinted $\mathrm{X}$ inactivation during early mouse development. Science 303 (5658), 644-649 (2004).

6 Skuse DH. X-linked genes and mental functioning. Hum. Mol. Genet. 14(Suppl. 1), R27-R32 (2005).

7 Sui Y, Chen Q, Sun X. Association of skewed X chromosome inactivation and idiopathic recurrent spontaneous abortion: a systematic review and meta-analysis. Reprod. Biomed. Online 31(2), 140-148 (2015).

8 Levin JH, Kaler SG. Non-random maternal X-chromosome inactivation associated with phaces. Clin. Genet. 72(4), 345-350 (2007).

9 Knudsen GP, Neilson TC, Pedersen J et al. Increased skewing of X chromosome inactivation in Rett syndrome patients and their mothers. Eur. J. Hum. Genet. 14(11), 1189-1194 (2006). dysfunction of its ability to differentiate into intended mature cells. Loss of $\mathrm{Xi}$ in cancer may represent unexpected retro-differentiation.

The single X/Y separates male from female. In addition to women's unique diseases in reproductive organs, many other diseases also have clear gender preferences. Whether this can be explained by the unique process of $\mathrm{Xi}$ in women is an interesting question. Although we have learned much over the past few decades, much more needs to be learned and more complex and well-thought studies are essential.

\section{Financial \& competing interests disclosure}

This work is partly supported by the independent research funds from the Mayo Clinic Center for Individualized Medicine and the National Natural Science Foundation of China (number 81202142). The authors have no other relevant affiliations or financial involvement with any organization or entity with a financial interest in or financial conflict with the subject matter or materials discussed in the manuscript apart from those disclosed.

No writing assistance was utilized in the production of this manuscript.

10 Lose F, Duffy DL, Kay GF, Kedda MA, Spurdle AB. Skewed $\mathrm{X}$ chromosome inactivation and breast and ovarian cancer status: evidence for X-linked modifiers of BRCA1. J. Natl Cancer Inst. 100 (21), 1519-1529 (2008).

11 Knudsen GP, Pedersen J, Klingenberg O, Lygren I, Orstavik $\mathrm{KH}$. Increased skewing of $\mathrm{X}$ chromosome inactivation with age in both blood and buccal cells. Cytogenet. Genome Res. 116(1-2), 24-28 (2007).

12 Orstavik KH. Skewed X inactivation in healthy individuals and in different diseases. Acta Paediatr. Suppl. 95(451), 24-29 (2006).

13 Kristiansen M, Langerod A, Knudsen GP, Weber BL, Borresen-Dale AL, Orstavik KH. High frequency of skewed $\mathrm{X}$ inactivation in young breast cancer patients. J. Med. Genet. 39(1), 30-33 (2002).

14 Kristiansen M, Knudsen GP, Maguire P et al. High incidence of skewed $\mathrm{X}$ chromosome inactivation in young patients with familial non-BRCA1/BRCA2 breast cancer. J. Med. Genet. 42(11), 877-880 (2005).

15 Buller RE, Sood AK, Lallas T, Buekers T, Skilling JS. Association between nonrandom X-chromosome inactivation and $B R C A 1$ mutation in germline DNA of patients with ovarian cancer. J. Natl Cancer Inst. 91(4), 339-346 (1999).

16 Li G, Su Q, Liu GQ et al. Skewed X chromosome inactivation of blood cells is associated with early development of lung cancer in females. Oncol. Rep. 16(4), 859-864 (2006).

17 Li G, Jin T, Liang H et al. Skewed X-chromosome inactivation in patients with esophageal carcinoma. Diagn. Pathol. 8, 55 (2013).

18 Helbling-Leclere A, Lenoir GM, Feunteun J. Heterozygote BRCA1 status and skewed chromosome $\mathrm{X}$ inactivation. Fam. Cancer 6(1), 153-157 (2007). 
19 Kristiansen M, Helland A, Kristensen GB et al. $\mathrm{X}$ chromosome inactivation in cervical cancer patients. Cancer Genet. Cytogenet. 146(1), 73-76 (2003).

20 Zheng J, Deng J, Jiang L et al. Heterozygous genetic variations of FOXP3 in Xp11.23 elevate breast cancer risk in Chinese population via skewed X-chromosome inactivation. Hum. Mutat. 34(4), 619-628 (2013).

21 Otter M, Schrander-Stumpel CT, Curfs LM. Triple $\mathrm{X}$ syndrome: a review of the literature. Eur. J. Hum. Genet. 18(3), 265-271 (2010).

22 Moraes LM, Cardoso LC, Moura VL et al. Detailed analysis of X chromosome inactivation in a 49, XXXXX pentasomy. Mol. Cytogenet. 2, 20 (2009).

23 Wang N, Cedrone E, Skuse GR, Insel R, Dry J. Two identical active $\mathrm{X}$ chromosomes in human mammary carcinoma cells. Cancer Genet. Cytogenet. 46(2), 271-280 (1990).

24 Richardson AL, Wang ZC, De Nicolo A et al. $\mathrm{X}$ chromosomal abnormalities in basal-like human breast cancer. Cancer Cell 9(2), 121-132 (2006).
25 Sirchia SM, Tabano S, Monti L et al. Misbehaviour of XIST RNA in breast cancer cells. PLoS ONE 4(5), e5559 (2009).

26 Sun Z, Prodduturi N, Sun SY, Thompson EA, Kocher JA. Chromosome $\mathrm{X}$ genomic and epigenomic aberrations and clinical implications in breast cancer by base resolution profiling. Epigenomics 7(7), 1099-1110 (2015).

27 Chaligne R, Popova T, Mendoza-Parra MA et al. The inactive $\mathrm{X}$ chromosome is epigenetically unstable and transcriptionally labile in breast cancer. Genome Res. 25(4), 488-503 (2015).

28 Kang J, Lee HJ, Jun SY, Park ES, Maeng LS. Cancer-testis antigen expression in serous endometrial cancer with loss of X chromosome inactivation. PLoS ONE 10(9), e0137476 (2015).

29 Pasque V, Plath K. X chromosome reactivation in reprogramming and in development. Curr. Opin. Cell. Biol. 37, 75-83 (2015).

30 Pasque V, Tchieu J, Karnik R et al. X chromosome reactivation dynamics reveal stages of reprogramming to pluripotency. Cell 159(7), 1681-1697 (2014). 